\title{
Older people and Social Quality - what difference does income make?
}

\author{
Liam Foster*, Mark Tomlinson and Alan Walker \\ Department of Sociological Studies, University of Sheffield, UK \\ ${ }^{*}$ Corresponding author. Email: L.Foster@sheffield.ac.uk
}

(Accepted 28 March 2018; first published online 2 July 2018)

\begin{abstract}
This article explores the relationship between Social Quality and income in later life and represents the first application of the concept to a United Kingdom data-set with an explicit focus on older people. In order to undertake this analysis, confirmatory factor analysis models are employed in conjunction with the British Household Panel Survey (BHPS). This enables various dimensions or domains of Social Quality to be measured and then subjected to further scrutiny via regression analysis. Initially, the paper explores links between low income, poverty and older people, prior to outlining the concept of Social Quality and its four conditional factors. Following the methodology, the impact of income on Social Quality domains is explored. We identify that differences in income in older age provide a partial explanation of differences in individual Social Quality. While there is a statistically significant relationship between income and certain aspects of Social Quality such as economic security, altruism, social networks and culture/participation, other factors such as health, identity and time did not have a statistically significant relationship with income. This indicates that improvements in the income of older people are likely to positively impact on aspects of their Social Quality. Finally, some policy implications of the finding are outlined with particular reference to the potential role for pensions in enhancing aspects of Social Quality in retirement.
\end{abstract}

Keywords: Social Quality; older people; pensions; British Household Panel Survey (BHPS); confirmatory factor analysis; poverty

\section{Introduction}

The increase in longevity that underlies population ageing is a remarkable social achievement and should be celebrated. In the United Kingdom (UK), life expectancy at age 65 is 20.8 years for women and 18.3 years for men on average (Office for National Statistics (ONS) 2014). It is estimated that the population aged over 65 will grow twice as fast as those of working age, accounting for 24 per cent by 2037 (ONS 2015a). While the incomes of pensioners have risen faster than average in recent years, there are still a large number of older people living on

(c) Cambridge University Press 2018. This is an Open Access article, distributed under the terms of the Creative Commons Attribution licence (http://creativecommons.org/licenses/by/4.0/), which permits unrestricted re-use, distribution, and reproduction in any medium, provided the original work is properly cited. 
low incomes in retirement (Age UK 2014). This presents challenges for policy makers and has resulted in questions about the role of pensions in particular in eradicating low incomes and poverty in older age, and in turn about pension system sustainability (Barr and Diamond 2008; Foster and Ginn 2015). It is within this context that it is important to ask what are the implications of low income, resulting in part from inadequate pension income, for people's wider social status in older age.

This focus on income is particularly appropriate given that it tends to decline in later life due to retirement, whilst health-related expenses tend to rise (Stoller and Stoller 2003). Furthermore, increasing life expectancy means that financial resources need to be maintained over an extended period (Hill et al. 2007) at a time when new flexibilities regarding annuities in defined contribution pension schemes have been introduced (Price et al. 2016). The management of finances can also be 'de-stabilised by unexpected and sudden changes' in the economy (Bornat and Bytheway 2010: 191). For instance, the financial crisis led to higher unemployment, lower growth, increasing national debt and financial market volatility, making it harder for all systems to deliver on pension promises (Ebbinghaus 2011). Such challenges may have an adverse impact upon the financial status of older people.

Policy makers have long been concerned with measuring and comparing the wellbeing of societies, communities and individuals. However, these measures have focused almost exclusively on different versions of individual quality of life, a tendency that may be noted in gerontology too (Lawton 1983; Mollenkopf and Walker 2007). In contrast, the defining feature of Social Quality is its concentration on the quality of overall social relations (van der Maesen and Walker 2012). Furthermore, in methodological terms, while quality-of-life measures are usually eclectic and often open-ended in their selection of indicators, Social Quality is limited to a theoretically grounded set of conditional factors (see below) that cannot vary according to the particular interests of the social scientists applying them. Of the many other competing concepts in the wellbeing field, including Sen's (1985) notion of 'capabilities' and the related concept of human security (Gasper et al. 2013), the only other one that strongly emphasises social relations is social capital. Unfortunately, this concept is difficult to pin down. For example, there are two distinct forms of it in the literature: capital analogous to economic capital, and social glue, analogous to social cohesion (Phillips 2006). In either form, it is definitely not a measure of societal quality or wellbeing, its focus is more microoriented, towards networks. Thus, its usefulness lies primarily in distinguishing properties in networks which may be either translated into other forms of 'capital' or used to enhance or diminish wellbeing. The social cohesion variant of social capital only considers one dimension of societal quality, other critical ones, such as social inclusion, socio-economic security and social empowerment, are neglected but, with social cohesion, form the basic conditional factors of Social Quality (see below). Social Quality differs in another important respect from other similar concepts in that it has an overt political dimension. It was specifically intended to provide both a policy instrument and a tool by which citizens could gain insights into the relative quality of their societies (Beck, van der Maesen and Walker 1998). Thus, in practical terms, it could be utilised to assist policy makers to understand 
characteristics that impact upon older people's lives better and facilitate better targeting of government actions (Povey et al. 2016).

Focusing on the relationship between Social Quality and income in later life represents the first application of the concept to a UK data-set with an explicit focus on older people. Testing in other policy areas has taken place in a range of comparative projects in Europe and Asia (Abbott and Wallace 2010, 2012, 2014; Lin 2013; Yee and Chang 2011), but it has only once before been applied to UK data-sets (Tomlinson, Foster and Walker 2016). The concept is applied here to explore the relationship between income and various aspects of Social Quality amongst retired individuals and couples. To facilitate this analysis, we employ confirmatory factor analysis (CFA) models in conjunction with the British Household Panel Survey (BHPS). These models allow the various domains of the four conditional factors of Social Quality to be measured and then subjected to further scrutiny via regression analysis.

Initially, the paper provides background on low income, poverty and older people, before the concept of Social Quality and its four conditional factors are presented. It then briefly outlines previous discussions regarding links between older people's incomes and their situation in retirement before the methodology is discussed, specifying how Social Quality has been operationalised using the BHPS. The impact of income on specific Social Quality domains is then analysed. Then the policy implications of the findings are outlined with particular reference to the need for adequate pension income to assist people to obtain a sufficient level of Social Quality in retirement. The results reveal that income is significantly associated with Social Quality in older age but not in all domains. This indicates that improving the incomes of older people is likely to have a positive impact on important aspects of their Social Quality but, also, that further research is required to identify other important influences. Finally, we estimate the income threshold for a sufficient level of Social Quality in the domain of socio-economic security.

\section{Older people, low income and poverty}

Low or modest incomes among older people are not uncommon. On average, the incomes of pensioners are lower than non-pensioners (Hills, Cunliffe and Obolenskaya 2016). However, older people are less likely to be in poverty than the population in general when using after-housing-costs measures. Before housing costs, however, single pensioners are more likely than many other groups to be in poverty. There have been significant changes in the patterns of poverty across the UK population. In the 1960 s and 1970 s, poverty rates were much higher for pensioners than for the rest of the population, for instance, around six to eight times as high as for working-age adults without children. However, substantial and sustained falls in pensioner poverty since the late 1980s, and increases in poverty rates among the rest of the population, mean that pensioners' risks of poverty compared to the rest of the population have largely reduced (Cribb et al. 2013). However, it is common for older people's income to cluster around the poverty line (Price 2006). About 1.1 million older people live on incomes just above the poverty line - that is between 60 and 69 per cent of median income (Age UK 2014). Given that many older people rely on benefits in retirement, poverty rates 
after housing costs reflect the position that pensioners' means-tested benefits tend to be higher than those for younger age groups (Age UK 2014). For instance, older people claiming Pension Credit and means-tested benefits to help with housing costs will normally be left with an income just above the poverty level following paying rent and Council Tax, whereas for many younger people benefits will not result in them being above the poverty line. However, means-tested benefits suffer from chronic non-take-up. For example, although it is in principle redistributive, around a third of those entitled to Pension Credit do not claim it, losing an average of $£ 34$ a week (Department for Work and Pensions (DWP) 2012).

There are considerable differences in the incomes of older people. These largely reflect individual's different lifecourse experiences, including their earnings and pension contributions (Foster 2010; Walker 2009). Fragmented work histories and low wages in particular have tended to play a role in low income in retirement (Age UK 2014; Blackburn, Jarman and Racko 2015). These are characteristics which have been particularly prevalent in women's employment, often with adverse effects on their retirement income (Ginn and MacIntyre 2013). Higher educational qualifications are also associated with lower levels of income poverty among older people. For instance, Glaser et al. (2009) found that 34 per cent of men with no educational qualifications had family incomes below the poverty line in comparison to 5 per cent of those with a higher degree. This is likely to have an instrumental effect on Social Quality by influencing factors such as income and wealth (Povey, Boreham and Tomaszewski 2016).

Income sources among older people consist mainly of pensions, supplemented by interest on savings, means-tested social assistance and other income transfers (Strauss 2014). Adequate pensions and especially private (non-state) pensions can substantially decrease the chances of poverty in retirement, but they are not accessible to all equally, as becomes apparent when the UK pensioner population is ranked by income. The average weekly occupational pension income (20102013 ) is $£ 435$ for the top fifth (quintile) of pensioner couples and $£ 207$ for the top quintile of single pensioners compared with $£ 27$ for the bottom quintile of pensioner couples and just $£ 9$ for single pensioners in the bottom quintile (DWP 2014). The poorest pensioners hold virtually all of their wealth in pensions whereas wealthy pensioners have large amounts of non-pension assets (Foster 2014). While pension systems play a major role in the distribution of retirement income, older people may have access to additional income or access to resources (which can include benefits-in-kind such as free television licences, eye tests, fuel and transport, as well as subsidised housing). The distribution of wealth and assets and the national policies associated with these, including interest rates and taxation, also have an important impact on poverty in older age.

People are unlikely to feel they have sufficient income to meet their needs if they are unable to replicate a standard of living in retirement close to the one to which they were accustomed prior to retirement. The Pensions Policy Institute (2009) has calculated that for people on median earnings, two-thirds of working lifetime income (after subtracting income tax) in retirement could allow similar consumption levels to those during working life (expenses are reduced in retirement, partly due to lower income taxes and National Insurance). Retired people also tend to save less of their income (e.g. in pensions), and are less likely to be paying mortgages or 
supporting dependants. So the total equivalised household expenditure reduces markedly as people get older: from an average of $£ 286$ per week among households headed by someone in their early fifties, to $£ 160$ per week among those headed by someone aged $80+$. But as people get older, they spend a greater proportion of money on life's essentials. Households headed by someone aged $80+$ spend double on housing, fuel and power compared to those in their early fifties (24\% compared to $12 \%$ ) (International Longevity Centre-UK (ILC-UK) 2014). Furthermore, a higher replacement rate is required for those on a low income prior to retirement to stay above the poverty line.

The Joseph Rowntree Foundation produces 'a minimum income standard for the UK' (MIS) each year. This provides the income required by different households based on the costs of items and services members of the public believe are needed to reach a minimum acceptable standard of living which enables household members to participate fully in society. In 2016, this figure was estimated at $£ 267.39$ per week for a pensioner couple or $£ 186.77$ for a single pensioner, after housing costs (Davis et al. 2016). As such, if pensioners are claiming Pension Credit, arguably they should have an income in line with the minimum income required for an appropriate standard of living (Age UK 2014). However, pensioners in the tax year $2016 / 2017$ could top up their weekly income to a guaranteed minimum of $£ 155.60$ if they were single or $£ 237.55$ if they were a couple (the Savings Credit could add an additional $£ 13.07$ per week for single pensioners or $£ 14.75$ per week for pensioner couples) - some way short of the MIS. Following from this, the question for this analysis is what impact the disparate levels of income in old age have on the societal quality experienced by pensioners.

\section{Assessing the quality of the social}

The concept of Social Quality emerged in the 1990s from debates about the neoliberal policy direction being taken in much of the European Union (EU). This emphasised an overly economistic notion of Europe as market-driven and was at odds with the rich heritage of welfare states, which reflected countless progressive social reform movements. The critical importance of social relations, as opposed to economic ones, had been largely overlooked. While this observation reflected earlier critiques of economic imperialism (Walker 1984) and the tendency for social policy to take a subordinate role in relation to economic management (Titmuss 1974), it also echoed academic investigations into the nature of the social (Bhaskar 1978; Elias 2000; Habermas 1989).

It was argued that attention to the quality of the social environment is required, as well as ubiquitous economic growth-oriented assessments of national wellbeing. Thus, Social Quality is defined as 'the extent to which people are able to participate in the social, economic and cultural lives of their communities under conditions which enhance their wellbeing and individual potential' (Beck, van der Maesen and Walker 1998: 3; van der Maesen and Walker 2012: 1). It is based on the fundamental assumption of the essential social nature of human beings, in contrast to the individualistic economic actors of neoliberalism. The 'social' is the process whereby people strive to achieve self-realisation in the context of the various collective identities they are part of over their lives. Therefore, individual identity is 
moulded by society through the process of social recognition (Honneth 1995). This process is framed by two sets of tensions: between individual or biographical development and societal development (micro and macro) and between institutions and organisations, on the one hand, and families, groups and communities, on the other (system and lifeworld). For this social process to take place in any locality or society, there have to be some basic requisites. For instance, social recognition or mutual respect, human rights and the rule of law (personal security), personal competence (the ability to act in a social environment) and the openness of societal collectivities (social responsiveness) (van der Maesen and Walker 2012).

This, in essence, is the theoretical underpinning of Social Quality. Its empirical measurement focuses on four conditional factors which regulate the extent to which people can participate socially under conditions that enhance their wellbeing and potential:

- Socio-economic security: levels of command over material and other resources over time.

- Social cohesion: the extent to which norms and values are accepted and shared.

- Social inclusion: the extent to which people have access to and are integrated into the wide variety of institutions and social relations which constitute everyday life.

- Social empowerment: the extent to which social structures, relations and institutions enhance individuals' personal capabilities as social actors.

The relationship between these factors and the framing structure of social relations referred to above are illustrated in Figure 1. This model has been successfully operationalised in cross-country comparative research in Europe (East and West) (Abbott and Wallace 2010, 2012, 2014), East Asia (Lin 2013; Yee and Chang 2011) and the UK in relation to low pay in working-age adults (Tomlinson, Foster and Walker 2016) - the only application to a UK data-set. Its application here is particularly important because the concept has not been applied to older age groups and the previously identified links between income and Social Quality during working life (Tomlinson, Foster and Walker 2016).

\section{Older people, income and social quality}

There is no research which analyses income among older people using the theory of Social Quality. However, the relationship between some of the conditional factors and domains of Social Quality have been considered in relation to income, although the findings have often been inconclusive and are dependent on the specific characteristics utilised to consider wellbeing or quality of life (Lloyd 2015). Some authors have found income insignificant when controlling for factors such as marital status, self-rated health and depression (Waddell and Jacobs-Lawson 2010) and neighbourhood services, security, social capital and social cohesion (Cramm, van Dijk and Nieboer 2012). Others have observed a small statistically significant relationship between older people's income and wellbeing (Pinquart and Sorensen 2000; Lloyd 2015). It has also been found that although many older people manage on a low income, those who find budgeting problematic, especially in relation to 


\section{Societal development}

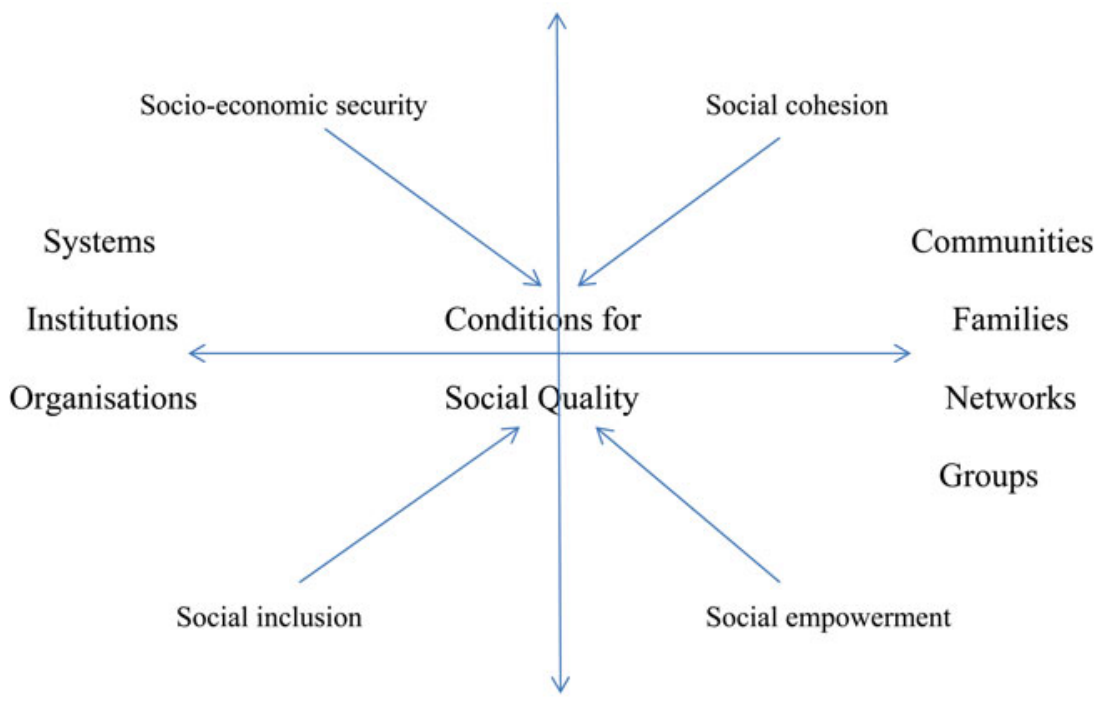

Biographical development

Figure 1. The conditional factors of Social Quality.

Source: van der Maesen and Walker (2012: 61).

debts, suffer mentally (Age UK 2011). Furthermore, the security of income is deemed to be particularly important to older people, as well as the actual amount (ILC-UK 2014).

Easterlin (1974) argued that income affects people's social wellbeing, but concluded that this was only relative to other changeable factors including expectations, adaptation levels and social comparisons (such as with their neighbours). For instance, older adults may simply adjust their expectations to their current financial situation (Pinquart and Sorensen 2000), reducing the relevance of income factors on their Social Quality. In contrast to this 'relativist' thesis, Veenhoven (1988) provides an 'absolutist' explanation, claiming that income affects one's wellbeing by enabling individuals to meet certain universal needs. An ONS (2015b) report also stated that individuals in households with higher incomes report higher levels of life satisfaction and happiness when controlling for other factors. However, when these needs have been met, income becomes less important for one's wellbeing as a result of the declining marginal utility of money. This suggests that the effect of income on wellbeing is stronger in households with lower incomes but becomes weaker as we move along the distribution. In other words, the same amount of money 'buys' more wellbeing for poorer people than it does for the rich (Povey, Boreham and Tomaszewski 2016). These observations are consistent with the findings in other Western countries (Diener and Biswas-Diener 2002).

Lloyd (2015), using the English Longitudinal Study of Ageing, found a relatively small impact of income on retirement satisfaction. Whilst this measure differs 
from Social Quality, it does offer some useful insights. The results showed that economic wellbeing (which is measured by income and wealth) increased overall wellbeing, but that the effect of income is a nuanced one. The impact of an increase in income on satisfaction in retirement was quite small, even in the case of relatively large increases in income, indicating that a rise in income does not in practice generate significantly increased wellbeing. This analysis did find that relative income plays a significant role, with retirees appearing to value having income similar to or above the typical amount relative to their environment, in accordance with Veenhoven (1988).

Research focusing specifically on older people has identified that they are less likely than others to complain about being on a low income (Age UK 2014). By the time people get to older age, they may have become accustomed to their circumstances in relation to certain life characteristics and, as such, may not identify the need for additional income (Bowling 2005). They are also less likely than other sections of the population to report not having items because of a lack of financial resources (the 'enforced lack' criterion) (Hick 2013). Hill, Sutton and Hirsch (2011), in interviews with older people, found that many people's needs and priorities had changed and that they did not necessarily need or want to spend money on things that they might previously have done. This included not wanting to go out in the evening or not missing a car and not spending on possessions. These types of attitude demonstrate the complexity involved when trying to understand why older people may be more likely to appear satisfied in circumstances that others might perceive as deprivation (Berthoud, Blekesaune and Hancock 2006; McKay 2008). However, for other older people, their financial circumstances in retirement may require them to cut back on recreational and cultural activities, even when they wanted to continue these, factors which have been identified as being important to contentment and health in later life (Bowling 2005; ILC-UK 2014).

Focusing on differences in Social Quality associated with age may be influenced by cohort and period effects. Age effects are essentially the consequences of growing older, while period effects are the result of influences that vary through time, and cohort effects are associated with being born at different times. For instance, those born in a particular cohort are influenced by the societal, cultural, political and economic context prevailing at different times in an individual's lifecourse (Dannefer 2003; Dewilde 2012; Elder 1975). Different cohorts of adults may come to retirement with widely divergent access to resources and the prospect of very different post-retirement experiences as a result. As such, estimating age effects is particularly challenging because these effects may be confounded by period or cohort effects.

It is evident that previous research has indicated a complex relationship between income and wellbeing in later life but none of it has investigated the consequences for social relations. This highlights the need to operationalise Social Quality in order to explore its links with income among older people. The key question being how far the effects of income differ according to the four conditional factors and their domains. 


\section{Data and methods}

In order to utilise Social Quality as a concept, the relationship between retired individuals and income is explored using the four conditional factors described previously. The analysis utilises data from the BHPS. The BHPS commenced in 1991 with an initial representative sample of around 10,000 individuals resident in some 5,000 households. These individuals have subsequently been re-interviewed each year and the sample has also been extended to involve more households from Scotland and Wales as well as to include Northern Ireland. Booster samples have also been incorporated to combat attrition. The data analysed below are limited to the last wave available (2008/2009) and to individuals who are self-declared as retired (only $2.9 \%$ of the sample were under 60 years old). The analysis was undertaken at the individual level, but could include two individuals from the same household where both members of the household are retired. That is, the analysis was restricted to those households with either a single pensioner or couples with at least one retiree and where the retiree's spouse is not in employment. The BHPS is unique in that it enables a comprehensive overview of all four conditional factors of Social Quality simultaneously, unlike its replacement - the UK Household Longitudinal Survey (UKHLS) - which no longer has the breadth of questions within a single wave that the BHPS had. In doing so, we omit employment-related characteristics from the Social Quality models as these characteristics are not applicable to the sample. We initially employed structural equation models (SEMs), as described below, to measure dimensions of Social Quality and relate these to income along with controls for age, gender and whether someone is single or in a couple. Income was measured at the household level and equivalised to account for household size using the McClement's before-housing-costs scale. The logarithm was also taken to help correct for skewness.

\section{First-order CFA models}

SEMs can be used to measure or test the validity of latent concepts, such as social inclusion, using CFA models. Several studies in sociology and social policy have used this type of modelling to estimate dimensions such as wellbeing, quality of life and multi-dimensional aspects of poverty in recent times (Heyes, Tomlinson and Whitworth 2017; Tomlinson, Foster and Walker 2016; Tomlinson, Walker and Williams 2009). A first-order CFA, which is used in this article, attempts to measure underlying latent concepts. Latent concepts are not directly observed, but can be estimated by associating them with observed manifestations of those concepts (i.e. by relating manifest variables with latent factors).

The SEM approach has certain advantages over traditional forms of exploratory factor analysis (EFA) such as principal components (see e.g. Byrne 2011; Kline 2015). With EFA, the analyst prepares a set of variables and the method finds associations between them and groups variables together into a set of factors which have to be interpreted by the analyst depending on the loadings relating the observed variables to each factor identified by the procedure. CFA has the distinct advantage that, given strong theoretical reasons to do so, the manifest variables associated with the factors required are determined in advance. In our case, the theory behind the Social Quality concept determines which variables should be 
associated with a set of predetermined factors or domains. Thus, CFA is a natural method with which to proceed. Examples of how this works follow.

The left side of Figure 2 shows a simple example of a CFA which has two latent unobserved variables: L1, housing; and L2, economic security. L1 is measured by the observed variables $\mathrm{V} 1-\mathrm{V} 4$ and $\mathrm{L} 2$ is measured by reference to variables V5-V7. V1-V4 might be answers from a respondent in a survey to questions about their satisfaction with their housing, the space, heating, having no damp, and so on. V5-V7 might be answers pertaining to whether their finances are good, improving and whether they are in a position to save. Thus, they are directly observable manifestations of the underlying latent concept that we are trying to measure.

The single-headed arrows in the figure represent loadings in the model which show the strength of the association of each variable with the relevant factors. These are usually shown in standardised form after estimation, much like beta coefficients in regression analysis. The covariance between housing (L1) and economic security (L2) is represented by the double-headed arrow. Thus, the correlation between the factors can be calculated. Unlike traditional EFA which usually produces uncorrelated factors by design, CFA allows the analyst to decide whether factors are allowed to be correlated or not - in general though, CFA allows correlations between factors to be estimated. There are also associated error terms which are shown as the circles labelled e1-e7. Using statistical techniques such as maximum likelihood and making assumptions about the distributions of the latent variables and error terms in the model, the loadings and covariances can be estimated. In all SEMs, a variety of fit statistics is available to assess the validity of the models constructed, and gender and age categories are included (see the Appendix). Usually it is assumed that the observed variables in the model are continuous and that the distribution of the variables is multivariate normal. Modern SEM software such as MPlus can accommodate categorical observed variables. Fit statistics are employed to verify the validity of the model and hence whether the factors make empirical sense.

Finally, other covariates can be applied to any or all of the latent concepts in the model. In other words, regression equations can be directly built into the SEM to show the association of independent variables with the latent factors determined by the manifest variables. Thus, controls and other causal factors, such as gender, single versus couple, and income, can be taken into account within the modelling framework. The size and statistical significance of such covariates can be estimated in a manner somewhat analogous to Ordinary Least Squares regression. This makes the method very powerful in that it is possible to simultaneously estimate factors via their manifest/observed variables and determine which independent variables are causally related to these factors.

\section{Results and discussion}

\section{Relating CFA to social quality}

Using the BHPS from 2008, we have estimated models that measure the domains of the four conditional factors of Social Quality (socio-economic security, social 


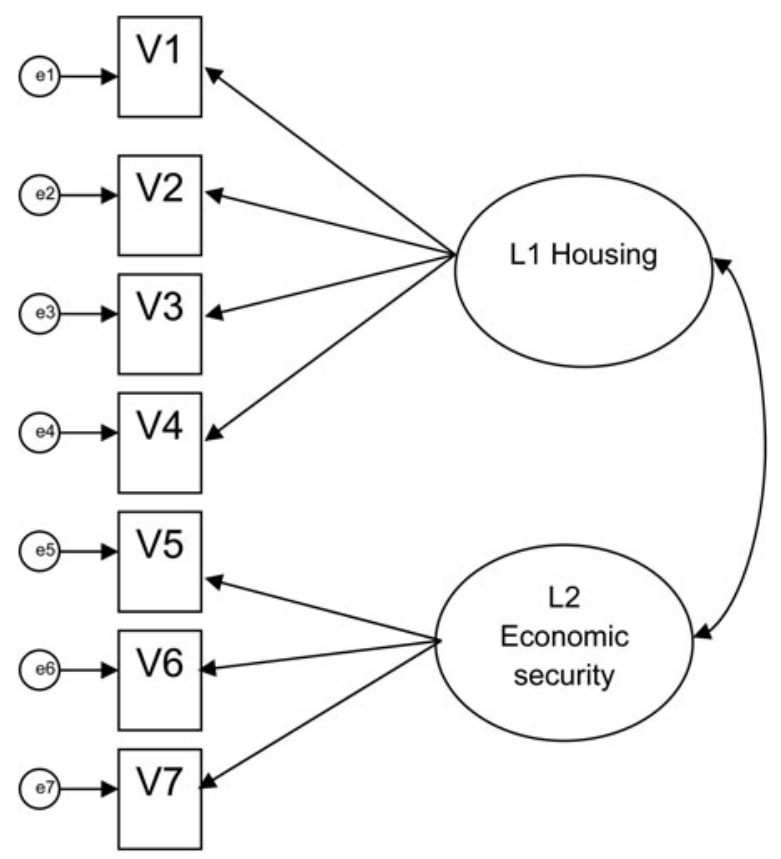

Figure 2. A simple first-order confirmatory factor analysis model.

Notes: L: latent unobserved variables. V: observed variables. E: error terms.

cohesion, social inclusion and social empowerment). For example, the first conditional factor was measured using a model shown in Figure 3. It is worth noting that the focus on individuals in retirement means that two domains including those related to employment are omitted from the model previously estimated for people in employment (Tomlinson, Foster and Walker 2016).

The variables employed to measure Social Quality using the four conditional factors are shown in Table 1. Four first-order CFA models were estimated, one for each conditional factor, and produced good-fit statistics. All manifest variables related to the factors in the models were statistically significant at the 1 per cent level. In the interests of brevity, we have not included the loadings related to each factor, but concentrate on the regression coefficients below. The loadings are not of direct interest, but rather the impact of independent variables such as income on the domains. The Appendix also shows the fit statistics for each firstorder model of the four conditional factors. In general Comparative Fit Index and Tucker-Lewis Index indices greater than 0.9 and Root Mean Square Error of Approximation figures below 0.05 are considered good. Thus, we can demonstrate that the four factors and their domains can be measured using CFA models.

\section{Multivariate analysis of sub-domains}

In order to differentiate the effects of income, we have estimated models with gender and whether someone is single or not as controls on each domain of the four conditional factors of Social Quality using income. This provides an indication of 

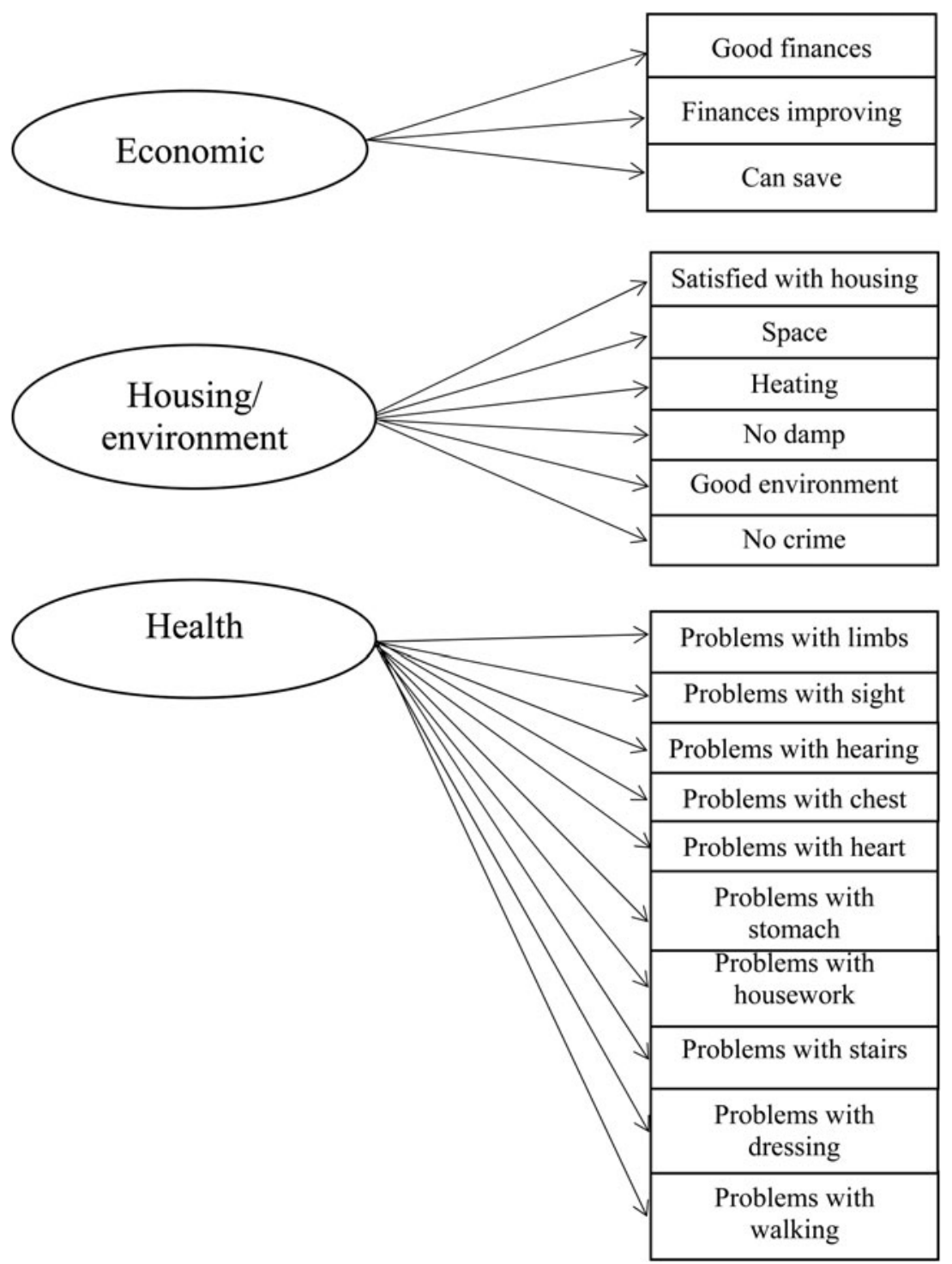

Figure 3. Example of a model of domains and the overall measure of the first domain (socio-economic security) using the British Household Panel Survey.

the differences in Social Quality experienced according to one's income. In each model the reference group is aged under 65, couple and male. The Appendix shows the coefficients and fit statistics for the covariates in the models for each domain.

It is worth acknowledging here that variations by older age and income may be less prominent as a result of differential mortality given that these are highest amongst those with lower incomes (Romeri, Baker and Griffiths 2006). Thus, 
Table 1. Variables used to identify Social Quality among retired individuals

\begin{tabular}{|c|c|}
\hline Latent domain & Measurement variables \\
\hline \multicolumn{2}{|c|}{ Conditional Factor 1: Socio-economic security } \\
\hline \multirow[t]{3}{*}{ Economic security } & Finances good \\
\hline & Finances improving \\
\hline & Can save \\
\hline \multirow[t]{6}{*}{ Housing/environment } & Satisfied with housing \\
\hline & Satisfied with space \\
\hline & Satisfied with heating \\
\hline & No damp \\
\hline & Good environment \\
\hline & No crime \\
\hline Health & $\begin{array}{l}\text { Problems with limbs } \\
\text { Problems with sight } \\
\text { Problems with hearing } \\
\text { Problems with chest } \\
\text { Problems with heart } \\
\text { Problems with stomach } \\
\text { Problems with housework } \\
\text { Problems with stairs } \\
\text { Problems with dressing } \\
\text { Problems with walking }\end{array}$ \\
\hline \multicolumn{2}{|c|}{ Conditional Factor 2: Social cohesion: } \\
\hline \multirow[t]{2}{*}{ Trust } & Trustworthiness of others \\
\hline & Close to a political party \\
\hline \multirow[t]{3}{*}{ Altruism } & Attend groups/voluntary organisations \\
\hline & Volunteer (unpaid) \\
\hline & Willingness to improve neighbourhood \\
\hline \multirow[t]{4}{*}{ Social networks } & Local friends mean a lot \\
\hline & Get advice from neighbours \\
\hline & Talk to neighbours \\
\hline & Borrow from neighbours \\
\hline \multirow[t]{3}{*}{ Identity } & Similar to neighbours \\
\hline & Like to stay in neighbourhood \\
\hline & Important to be British \\
\hline \multicolumn{2}{|c|}{ Conditional Factor 3: Social inclusion: } \\
\hline \multirow[t]{3}{*}{ Citizenship } & Voted \\
\hline & Interest in politics \\
\hline & Has a political party \\
\hline
\end{tabular}


Table 1. (Continued.)

\begin{tabular}{|ll}
\hline Latent domain & \multicolumn{1}{c}{ Measurement variables } \\
\hline Services & Access to medical services \\
& Access to transport \\
\hline Social networks & Access to shopping \\
\hline Access to leisure facilities \\
\hline Conditional Factor 4: Empowerment: & Frequency of talking to neighbours \\
\hline Knowledge & Frequency of meeting people \\
\hline Time & Satisfaction with social life \\
\hline Resources to entertain visitors \\
\hline Culture/participation & High education \\
\hline Internet at home \\
\hline Satisfaction with leisure time \\
\hline Satisfaction with use of leisure time \\
\hline Play sports \\
\hline Watch sports live \\
\hline Go to cinema \\
\hline Go to theatre \\
\hline Dine out \\
\hline Go to pubs/clubs \\
\hline
\end{tabular}

those who are less able at translating income into material wellbeing may have a tendency to die younger than those who are able to derive higher living standards from a given income, and this would explain why, as a cohort ages and when controlling for income, its surviving members benefit from a higher living standard (Berthoud, Blekesaune and Hancock 2009). However, this would not mean that an individual enjoys a higher living standard from a given income as he or she ages. Unfortunately, we are not able to estimate the likely extent of this differential. Furthermore, some of the effects in the models relating to age may well be cohort effects rather than age effects per se, but it is impossible to distinguish between the two (as it is not possible to include birth cohort and age in the same model).

\section{Social quality and income}

Figure 4 details the effects of income in each of the four Social Quality conditional factors. In order to interpret Figure 4, it is important to recognise that a one standard deviation shift in log-equivalised income results in a shift in the standard deviation of each domain shown by the length of each bar in the graph. Those domains which have the largest bars are influenced the most by income, whereas the smallest bars are often not significant. These findings are now discussed in turn. 


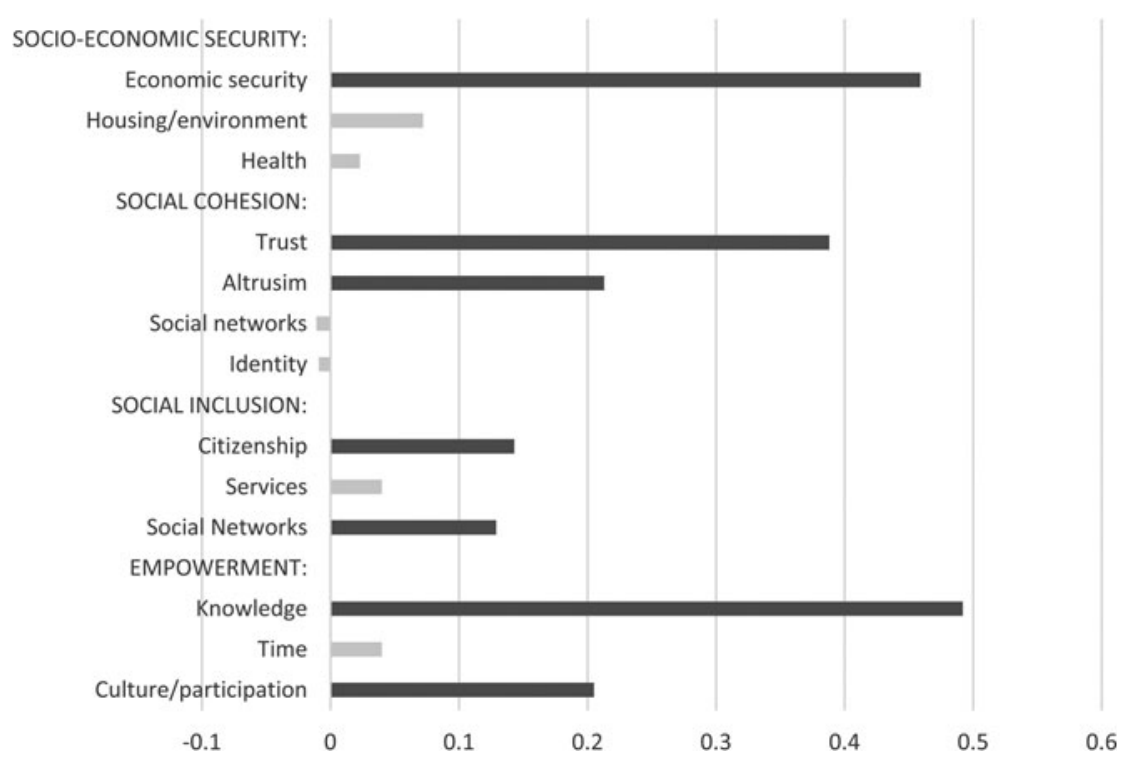

Figure 4. Standardised income coefficients.

Significance level: Black bars indicate significance at the 1 per cent level.

\section{Factor 1: Socio-economic security}

As one might expect, there is a statistically significant relationship between economic security, a domain of Factor 1 (which features the capacity to finance the purchase of goods and the opportunity to save), and income among older people. Economic security is viewed as an essential component of an individual's needs and local councils should consider this along with other areas, such as health, when undertaking social care assessments. Another domain, housing/environment, is not significantly associated with income in later life. While housing and environment can influence Social Quality, mainly through having good neighbours, living in a well-kept, safe neighbourhood and having a comfortable home, this is not necessarily related to income. This may be because, as previously stated, when people get to older age they may have become accustomed to their circumstances in relation to certain Social Quality, including housing. Scharf, Phillipson and Smith (2004) reported strong neighbourhood attachments among older people in highly deprived circumstances. Furthermore, Bowling (2005) found that increased income does not mean that people would want to move to a different house or area given that they may not access similar social networks.

Health is an important determinant of Social Quality. This is linked to mobility and independence (ILC-UK 2014). It may be expected that health and income have a statistically significant relationship, with those with poor health more like to face material deprivation, as this limits autonomy and independence as well as imposing additional costs of living. However, Glaser et al. (2009) and Lloyd (2015) both found that being in poor general health was associated with being in poverty, but, similarly to this study, there was little variation by the other health measures considered. For example, having a chronic health problem or difficulties with daily 
living was not statistically associated with low income. This may also be influenced by differences in mortality rates (Berthoud, Blekesaune and Hancock 2009). Table A1 in the Appendix unsurprisingly shows health deteriorates with advanced age and that this is statistically significant from age 75 onwards. This reflects the fact that morbidity from a number of diseases increases with age. These include musculoskeletal conditions (including low back and neck pain), neurological diseases (including Alzheimer's and other dementias) and diabetes (Public Health England 2017). Retired women are also less healthy than men after taking age and income into account, and women are also more prone to conditions such as arthritis, depression, brittle bones and dementia.

\section{Factor 2: Social cohesion}

Figure 4 shows that there was a significant association between income in later life and the latent domain of trust. Elsewhere it has been shown that income is associated with being a member of a political party, trade union or environmental groups (Lloyd 2015), and this was shown to be the case in this study. These greater levels of engagement and trust may be related to greater levels of political awareness and knowledge as a result of increased access to resources and finances to enable participation. There was also some evidence that trust increases with age, especially among those over 80 years of age. Increasing age was also associated with the greater likelihood of political party affiliation (Park et al. 2013), but gender was found to be non-significant. It was evident that there is significant relationship between altruism and income in older age. This was especially the case in relation to donations but also applicable to other forms of civic participation. Thus, it appears that the security provided by a greater income increased the chances of respondents feeling able to donate money (Breeze 2004), although this does decrease with advanced age as the over $75 \mathrm{~s}$ were less likely to be altruistic - a finding that is clearly worthy of further exploration. Women were more likely to be altruistic than men. This latent altruism domain includes the categories: attend volunteer groups and unpaid volunteering. Given that a European Commission (2010) survey shows that women are more likely to volunteer than men, this finding is not surprising. There are differences in the types of volunteering men and women undertake, because gender stereotypes continue to operate in the voluntary spheres of society, with the distribution of older men in volunteering more likely to be concentrated in the more prestigious roles such as 'honorary political offices', with older women concentrated in the less visible realm of 'social engagement' (Corsi and Samek Lodovici 2010).

There was no significant association between older people's income and the latent domains of social networks and identity. Social relationships with friends and family have been ranked among the most important factors positively influencing Social Quality among older people (Bowling et al. 2002; ILC-UK 2014). Valued interaction with friends and family members, as well as the existence of close relationships, can make a difference to a person's Social Quality, as well as having implications for risk and protective factors (Netuveli et al. 2006). However, these can be maintained regardless of income (and also do not appear to be influenced by age). In fact, lower levels of income may mean people are physically closer to neighbours and they may also be in a similar financial position relative to their 
neighbours (Bowling 2005). As such, income does not appear to affect one's identity negatively in older age. In practice, a socially cohesive society is marked by its supportiveness, shared value systems and identities, a sense of belonging, solidarity between groups and reciprocity (Kawachi and Berkman 2000). It was evident from the data that these characteristics are not necessarily increased by improvements in income. However, older respondents did have an increased sense of identity, especially from age 75 onwards. Women also had a marginally higher score in relation to identity (which includes whether people think they are similar to their neighbours) than men. This is likely to be associated with the tendency for older men (and single older men, in particular) to be less socially embedded and more isolated in relation to their neighbourhood (Davidson 2004). Wilkinson and Pickett (2009) argued that income inequalities may have a greater effect on wellbeing than income itself. They found that in countries where income inequalities are greatest, people are least likely to believe people can be trusted. They assert that high levels of trust mean people feel more secure, have less to worry about and see others as co-operative as oppose to competitive.

\section{Factor 3: Social inclusion}

In this particular conditional factor, citizenship is defined according to people's voting behaviour, interest in politics and whether they have a political party. It is apparent that there is a statistically significant relationship between income and citizenship. Such findings have also been identified elsewhere (Electoral Commission 2005). Voting behaviour disparity may be associated with the fact that lower-income people tend to be less educated and not as politically active in general. In contrast, wealthier people may be better connected to donors, community leaders and politicians who encourage them to vote. Those with a low income tend to be the most politically excluded and political disengagement can itself be a form of social exclusion. This is because when insufficient finances result in individuals feeling unable to exert any influence over the most basic elements of their life, they are more inclined to believe they are unable to make a difference in politics and policy making. In short, individuals from socially excluded groups have often had agency removed. Citizenship was also found to increase with age, but was significantly lower for women than men. Given that the variables associated with this domain focus on voting behaviour, interest in politics and whether someone has a political party, this is not surprising. For instance, women are less likely to vote than men and are consistently over-represented among undecided voters in the lead up to elections (Campbell and Childs 2015). Despite an increase in relation to the degree of gender equality in political power, women appear to participate actively in politics to a lesser extent than men (Fraile 2014). Access to services is not related to income among older people. Whilst this is important for one's Social Quality in older age (Walker and Walker 1997), access to services is made less financially problematic by free bus passes for people over 60 in many regions. In effect, neighbourhood services may act as a buffer against the adverse effects of being poor on the wellbeing of older adults, indicating the important role targeted community interventions can play in assisting someone's Social Quality (Cramm, van Dijk and Nieboer 2012). Elsewhere it has been shown that health does have a statistically significant relationship with services as ill-health can affect one's capacity to access 
resources (and may also have financial implications for travel arrangements) (Lloyd 2015). The final latent domain in the social inclusion factor relates to social networks (these are defined differently to social networks in the second factor (social cohesion) which focused on relationships with neighbours). This is largely focused on satisfaction with social life and having the resources to entertain visitors. Given that there are financial implications associated with some of these behaviours, including access to the financial resources required in order to entertain visitors, a statistically significant relationship between social networks and income in this instance is not surprising.

\section{Factor 4: Empowerment}

The first latent domain of empowerment is knowledge. This focuses on educational attainment and having the internet at home. As expected, there is a statistically significant relationship between these variables and Social Quality. It is wellestablished that education is associated with increased income as a result of better paid employment during the working life and subsequently higher income in the form of pensions and other investments in retirement (Blackburn, Jarman and Racko 2015; Ginn and MacIntyre 2013). Indeed, income and education are very highly correlated in the sample used for this analysis, to such an extent that including education variables in the regressions resulted in serious collinearity and had to be excluded. The more wealthy are more likely to be able to afford internet access too. It is also the case that knowledge declines with age, but this may well be a cohort effect rather than an ageing one. Women also appear to have lower knowledge resources than men, other things being equal. This will, in part, be associated with historical trends in their lower access to higher education in particular. For instance, while women are now more likely to attend university than men, in the 1960s only 25 per cent of full-time students in UK universities were women (Willets 2013). Furthermore, Age UK (2016) has identified that older women are less likely to use the internet than men.

The next latent domain is time. However, there is no statistically significant relationship between income and time in older age. This is likely to be associated with the fact that all of the individuals in the survey are retired from paid work, released from the structure and constraints that it placed on their lives. There will obviously be considerable differences in terms of how this time is utilised, with a growing number of older people undertaking caring responsibilities (Loretto and Vickerstaff 2015). The final latent domain in this conditional factor is culture/participation. It is evident from Figure 4 in the Appendix that those with higher incomes are more likely to participate in various activities. It has been shown that people with lower incomes have fewer resources to spend on leisure activities in retirement (Bowling 2005; Lloyd 2015). This, in turn, may impact negatively on their overall physical, mental and social situation (Silverstein and Parker 2002). An 'engaged lifestyle' is an important component of active ageing (Foster and Walker 2015). Not surprising, perhaps, participation in cultural activities declines with age (especially as a result of declining health; Public Health England 2017), and, although women are just as likely as men to engage, there are often gendered differences in the forms of engagement (Foster and Walker 2013). 


\section{Social quality, pensions and income}

It is evident that income has a statistically significant relationship with certain key aspects of Social Quality such as economic security, altruism, social networks and culture/participation. In order to benefit those Social Quality domains which are affected negatively by low income, it is important to highlight policy measures to enhance the income of older individuals. These include improvements in pension provision such as minimum standards for current pensioners. In the UK, the indexation of the basic pension and the means-tested Pension Credit have been improved and a new single-tier pension, combining the basic and second (earnings-related) state pensions, was introduced in 2016 at about $£ 155$ per week if payable in full. Since no extra funding is forthcoming, there will be both gainers and losers, with estimates of gainers varying from 35 per cent of men and 61 per cent of women (Crawford, Keynes and Tetlow 2013) to 70 per cent of men and 75 per cent of women (DWP 2015). Those low-paid individuals (among whom women are overrepresented) who have the full contribution/credits record of 35 years will be better off; but no derived benefits will accrue in the new pension as they are phased out. However, men and women already over state pension age (SPA) in April 2016 are ineligible and will continue to receive the state pension in its current form, even where they would have benefited from the new pension. If existing pensioners had been included, by 2025 this would reduce the projected percentage of pensioners living in relative poverty from around 11 per cent under current policy to around 7 per cent, rather than 10 per cent when just including those reaching the SPA post-2016 (Carrera, Redwood and Adams 2012). This would have potential implications for levels of Social Quality for a large number of people.

The financial situation of people in retirement is a result of the gradual accumulation of pensions and other assets over the lifecourse. Occupational inequality not only shapes experience in people's working lives, but also has the effect of determining experiences in later life (Blackburn, Jarman and Racko 2015). Low income in older age is a result of a lifetime of multiple and interconnected disadvantages (Walker 1981, 2009). Policies aimed at the role of private pensions in increasing provision for retirement are likely to bring about greater income inequality between those who have had an intermittent or low-paid employment history and those with an advantaged position in the labour market (Foster 2010). The notion of pension equality that assumes equitable outcomes will stem from a 'convergence on a single model of full-time, professional, well remunerated work with an employer who provides an occupational pension plan, [which] is clearly flawed and does not account for the realities of contemporary labour markets' (Strauss 2014: 534). Furthermore, it does not recognise the very different employment trajectories often experienced by women (Grady 2015). To prevent such inherent inequalities, there is a need to redevelop pension systems in a manner which de-couples income in retirement from labour market participation (Strauss 2014). One option is to introduce an unconditional individual Citizens' Pension, such as the longestablished and successful Dutch model. Such an approach could promote greater equality by ensuring that the pension is set at a level to provide a sufficient level of Social Quality in relation to the domains which are particularly influenced by income. 


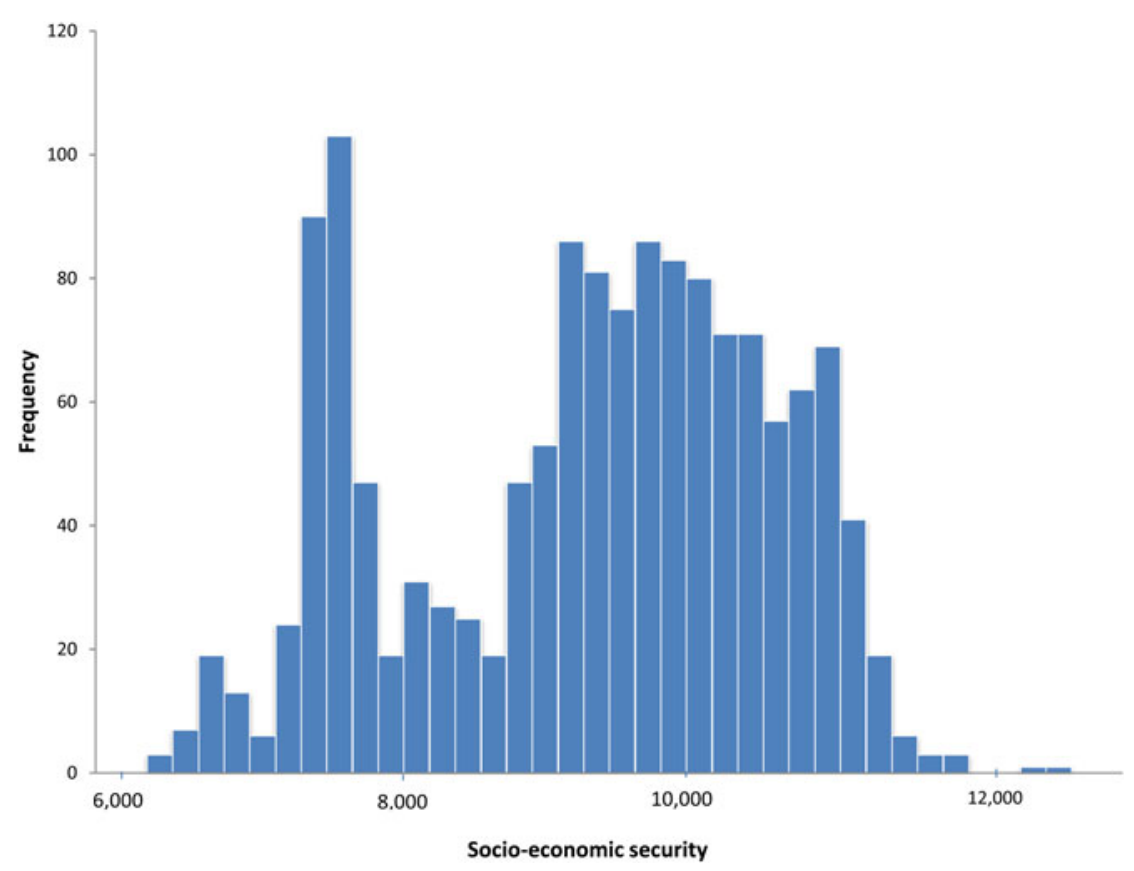

Figure 5. Histogram of socio-economic security scores for pensioner couples.

To illustrate the potential policy value of such an approach and to pave the way for further research, we estimated the minimum income threshold that would provide a basic level of Social Quality. We took the domain of socio-economic security and explored the three sub-dimensions of economic security, housing and health, and found that a basic model for pensioner couples produces distributions of Social Quality scores that are roughly bi-modal. What this suggests is that there are essentially two populations in the sample of retired couples: one with relatively low Social Quality and one with relatively high Social Quality. For example, see Figure 5 for socio-economic security. We estimated where the tail of the Social Quality poor group ends and the Social Quality rich group begins. This produced a threshold value for Social Quality. Then using a simple regression, we estimated the income required to reach this target. Our results suggest that for socioeconomic security, an average pensioner couple would require around $£ 15,240$ per annum in 2017 prices before housing costs to attain this threshold. We expect that the thresholds for the other three domains will be different but that is a subject for further research.

\section{Conclusion}

By using data from the BHPS, we have shown that differences in income in older age provide only a partial explanation of differences in individual Social Quality. While there was a statistically significant relationship between income and certain 
aspects of Social Quality such as economic security, altruism, social networks and culture/participation, other factors such as health, identity and time did not have a statistically significant relationship with income. The relative nature of the income effect is well established (Easterlin 1974; Pinquart and Sorensen 2000) in that the impact on Social Quality in older age may be relative to other changeable factors including expectations, adaptation levels and social comparisons. This indicates that as long as individuals are able to meet certain universal needs (Veenhoven 1988) and are in a similar situation to their neighbours, then income may not have a major impact on certain aspects of both wellbeing and Social Quality in older age. This opens the way for further research to explore other factors which may have effects on aspects of Social Quality in retirement, including the impact of health, neighbourhood, education, ethnicity and age cohort. Enhancing our understanding of the factors which affect Social Quality in later life provides an opportunity to explore policy measures to improve the older people's social environment. For instance, the analysis has shown that important aspects of Social Quality in older age could be enhanced by higher incomes which could be achieved by raising the state pension, and we have taken a significant step towards identifying the income threshold for a minimum level of Social Quality. In methodological terms, structural equation modelling has much to offer to the study of Social Quality in retirement.

Statement of ethical approval. This work did not require ethical approval.

\section{References}

Abbott P and Wallace C (2010) Explaining economics and social transformation in post Soviet Russia, Ukraine and Belarus - the social quality approach. European Societies 12, 653-674.

Abbott P and Wallace C (2012) Social quality: a way to measure the quality of society. Social Indicators Research 108, 153-167.

Abbott P and Wallace C (2014) Rising economic prosperity and social quality: the case of new member states of the European Union. Social Indicators Research 115, 419-439.

Age UK (2011) Still Hungry to Be Heard - in London. Age UK, London.

Age UK (2014) Age UK Evidence Review: Poverty in Later Life. Available online at http://www.futureyears. org.uk/uploads/files/Age\%20UK\%20on\%20poverty\%20in\%20old\%20age.pdf (Accessed 20 June 2016).

Age UK (2016) The Internet and Older People in the UK - Key Statistics. Available online at https://www. ageuk.org.uk/globalassets/age-uk/documents/reports-and-publications/reports-and-briefings/activecommunities/rb_july16_older_people_and_internet_use_stats.pdf (Accessed 10 December 2017).

Barr N and Diamond P (2008) Reforming Pensions: Principles and Policy Choices. Oxford: Oxford University Press.

Beck W, van der Maesen L and Walker A (eds) (1998) The Social Quality of Europe. Bristol, UK: Policy Press.

Berthoud R, Blekesaune M and Hancock R (2006) Are 'poor' pensioners 'deprived'? Research Report 364, Department for Work and Pensions, Corporate Document Services, Leeds, UK.

Berthoud R, Blekesaune M and Hancock R (2009) Ageing, income and living standards: evidence from the British Household Panel Survey. Ageing \& Society 29, 1105-1122.

Bhaskar R (1978) A Realist Theory of Science. Brighton, UK: Harvester Press.

Blackburn R, Jarman J and Racko G (2015) Understanding gender inequality in employment and retirement. Contemporary Social Science 11, 238-252.

Bornat J and Bytheway B (2010) Late life reflections on the downturn: perspectives from the oldest generation. 21st Century Society 5, 183-192.

Bowling A (2005) Ageing Well: Quality of Life in Old Age. Maidenhead, UK: Open University Press. 
Bowling A, Gabriel Z, Banister D and Sutton S (2002) Adding quality and quantity: older people's views on their quality of life and its enhancement. Research Findings 7, Growing Older Programme, Economic and Social Research Council, Swindon, UK.

Breeze B (2004) Widow's mite or widow's might? The relative giving of rich and poor in the UK. Paper presented at the 33rd annual conference of the Association for Research on Non-profit Associations and Voluntary Action, Los Angeles, 20th November 2004.

Byrne B (2011) Structural Equation Modeling with Mplus: Basic Concepts, Applications, and Programming. Routledge, Hove, UK.

Campbell R and Childs S (2015) All aboard the pink battle bus? Women voters, women's issues, candidates and party leaders. Parliamentary Affairs 68, 206-223.

Carrera L, Redwood D and Adams J (2012) An Assessment of the Government's Options for State Pension Reform. Pensions Policy Institute, London.

Corsi M and Samek Lodovici M (2010) Active ageing and gender equality policies. EGGSI Report for the European Commission, DG Employment, Social Affairs and Equal Opportunities, Brussels.

Cramm JM, van Dijk HM and Nieboer AP (2012) The importance of neighborhood social cohesion and social capital for the well being of older adults in the community. The Gerontologist 53, 142-152.

Crawford R, Keynes S and Tetlow G (2013) A Single-tier Pension: What Does it Really Mean? IFS Report R82, Institute for Fiscal Studies, London. Available online at www.ifs.org.uk/comms/r82.pdf (Accessed 30 July 2015).

Cribb J, Hood A, Joyce R and Phillips DG (2013) Living standards, poverty and inequality in the UK: 2013. IFS Report R81, Institute for Fiscal Studies, London.

Dannefer D (2003) Cumulative advantage/disadvantage and the life course: cross-fertilizing age and social science theory. Journal of Gerontology 58, S327-S337.

Davidson K (2004) 'Why can't a man be more like a woman?' Marital status and social networking of older men. Journal of Men's Studies 13, 25-37.

Davis A, Hill K, Hirsch D and Padley M (2016) A Minimum Income Standard for the UK in 2016. Joseph Rowntree Foundation, Loughborough, UK.

Department for Work and Pensions (DWP) (2012) Income Related Benefits: Estimates of Take-up in 2009-10. The Stationery Office, London.

Department for Work and Pensions (DWP) (2014) The Pensioners' Incomes Series 2012/13. The Stationery Office, London.

Department for Work and Pensions (DWP) (2015) Impact of New State Pension on an Individual's Pension Entitlement - First 15 Years. The Stationery Office, London.

Dewilde C (2012) Life course determinants and incomes in retirement: Belgium and the United Kingdom compared. Ageing \& Society 32, 587-615.

Diener E and Biswas-Diener R (2002) Will money increase subjective well-being? A literature review and guide to needed research. Social Indicators Research 57, 119-169.

Easterlin R (1974) Does economic growth improve the human lot? Some empirical evidence. In David P and Reder M (eds), Nations and Households in Economic Growth. Stanford, California: Stanford University Press, pp. 89-125.

Ebbinghaus B (ed.) (2011) The Varieties of Pension Governance: Pension Privatization in Europe. Oxford: Oxford University Press.

Elder G (1975) Age differentiation and the life course. Annual Review of Sociology 1, 165-190.

Electoral Commission (2005) Social exclusion and political engagement. Research Report, November, Electoral Commission, London.

Elias N (2000) The Civilising Process. Oxford: Blackwell.

European Commission (2010) Study of Volunteering in the European Union-Country Report United Kingdom. European Commission, Brussels.

Foster L (2010) Towards a new political economy of pensions? The implications for women. Critical Social Policy 30, 27-47.

Foster L (2014) Women's pensions in the European Union and the current economic crisis. Policy and Politics 42, 565-580.

Foster L and Ginn J (2015) Pensions and the Coalition: a new way forward? In Foster L, Brunton A, Deeming C and Haux T (eds), In Defence of Welfare 2. Bristol, UK: Social Policy Association with Policy Press, pp. 72-5. 
Foster L and Walker A (2013) Gender and active ageing in Europe. European Journal of Ageing 10, 3-10. Foster L and Walker A (2015) Active and successful aging: a European policy perspective. The Gerontologist 55, 83-90.

Fraile M (2014) Do women know less about politics than men? The gender gap in political knowledge in Europe. Social Politics 21, 261-289.

Gasper D, van der Maesen L, Truong T-D and Walker A (2013) Connecting 'human' and 'social' discourses: the human development, human security, and social quality approaches. In Hans-Uwe O and Ziegler H (eds), Enhancing Capabilities: The Role of Social Institutions. Opladen, Germany: Barbara Budrich.

Ginn J and MacIntyre K (2013) UK pension reforms: is gender still an issue? Social Policy \& Society 13, 91-103.

Glaser K, Nicholls M, Stuchbury R, Price D and Gjonça E (2009) Life Course Influences on Health and Well-being in Later Life: A Secondary Analysis. Equality and Human Rights Commission with Age Concern and Help the Aged, Manchester, UK.

Grady J (2015) Gendering pensions: making women visible. Gender, Work and Organization 22, 445-458.

Habermas J (1989) The Theory of Communicative Action. Oxford: Blackwell.

Heyes J, Tomlinson M and Whitworth A (2017) Underemployment and well-being in the UK before and after the Great Recession. Work, Employment and Society 31, 71-89.

Hick R (2013) Poverty, preference or pensioners? Measuring material deprivation in the UK. Fiscal Studies 34, 31-54.

Hill K, Kellard K, Middleton S, Cox L and Pound E (2007) Understanding Resources in Later Life. Joseph Rowntree Foundation, York, UK.

Hill K, Sutton L and Hirsch D (2011) Living on a Low Income in Later Life. Age UK, London.

Hills J, Cunliffe J and Obolenskaya P (2016) The changing structure of UK in quality since the crisis. In Lupton R, Burchardt T, Hills J, Stewart K and Vizard P (eds), Social Policy in a Cold Climate: Policies and Their Consequences Since the Crisis. Case Studies on Poverty, Place and Policy. Bristol, UK: Policy Press.

Honneth A (1995) The Struggle for Recognition. Oxford: Policy Press.

International Longevity Centre-UK (ILC-UK) (2014) Financial Wellbeing in Later Life: Evidence and Policy. ILC-UK, London.

Kawachi I and Berkman L (2000) Social cohesion, social capital, and health. In Berkman LF and Kawachi I (eds), Social Epidemiology. New York: Oxford University Press, pp. 174-190.

Kline RB (2015) Principles and Practice of Structural Equation Modeling. Fourth edition, London: The Guildford Press.

Lawton M (1983) Environmental and other determinants of well-being in older people. The Gerontologist 23, 349-357.

Lin K (2013) A methodological exploration of social quality research. International Sociology 28, 316-334.

Lloyd J (2015) Income, Security and Wellbeing: Helping Savers Choose a Good Retirement. Strategic Society Centre, London.

Loretto W and Vickerstaff S (2015) Gender, age and flexible working in later life. Work, Employment and Society 29, 233-249.

McKay S (2008) Measuring material deprivation among older people: methodological study to revise the Family Resources Survey questions. Department for Work and Pensions Working Paper 54, HMSO, London.

Mollenkopf H and Walker A (eds) (2007) Quality of Life in Old Age. Dordrecht, The Nertherlands: Springer.

Netuveli G, Hildon Z, Montgomery S, Wiggins R and Blane D (2006) Quality of life at older ages: evidence from English Longitudinal Study of Ageing. Journal of Epidemiology and Community Health 60, 357-363.

Office for National Statistics (ONS) (2014) National Life Tables, United Kingdom, 2011-2013. Available online at http://www.ons.gov.uk/ons/dcp171778_377972.pdf (Accessed 20 February 2016).

Office for National Statistics (ONS) (2015a) Wealth and Assets Survey 2015. ONS, London.

Office for National Statistics (ONS) (2015b) Relationship Between Wealth, Income and Personal Well-being, July 2011 to June 2012. ONS, London.

Park A, Bryson C, Clery E, Curtice J and Phillips M (eds) (2013) British Social Attitudes: The 30th Report. NatCen Social Research, London. 
Pensions Policy Institute (PPI) (2009) Retirement Income and Assets: Do Pensioners Have Sufficient Income to Meet Their Needs? PPI, London.

Phillips D (2006) Quality of Life: Concept, Policy and Practice. New York: Routledge.

Pinquart M and Sorensen S (2000) Influences of socioeconomic status, social network and competence on subjective well-being in later life: a meta-analysis. Psychology and Aging 15, 187-224.

Povey J, Boreham P and Tomaszewski W (2016) The development of a new multi-faceted model of social wellbeing: does income level make a difference? Journal of Sociology 52, 155-172.

Price D (2006) The poverty of older people in the UK. Journal of Social Work Practice 20, 251-266.

Price D, Glaser K, Ginn J and Nicholls M (2016) How important are state transfers for reducing poverty rates in later life? Ageing \& Society 36, 1794-1825.

Public Health England (2017) Health Profile for England. Available online at https://www.gov.uk/government/publications/health-profile-for-england (Accessed 25 September 2017).

Romeri E, Baker A and Griffiths C (2006) Mortality by deprivation and cause of death in England and Wales 1999-2003. Health Statistics Quarterly, 32, Winter, 19-34.

Scharf T, Phillipson C and Smith A (2004) Poverty and social exclusion-growing older in a deprived neighbourhood. In Walker A and Hagan-Hennessy C (eds), Growing Older. Maidenhead, UK: McGraw-Hill, pp. 81-106.

Sen A (1985) Commodities and Capabilities. New York: Oxford University Press.

Silverstein M and Parker MG (2002) Leisure activities and quality of life among the oldest old in Sweden. Research on Aging 24, 528-547.

Stoller M and Stoller E (2003) Perceived income adequacy among elderly retirees. Journal of Applied Gerontology 22, 230-251.

Strauss K (2014) Accessing pension resources: the right to equality inside and out of the labour market. International Journal of Law in Context 10, 522-537.

Titmuss RM (1974) Social Policy - An Introduction. Allen and Unwin, London.

Tomlinson M, Foster L and Walker A (2016) Social quality and work: what impact does low pay have on social quality? Journal of Social Policy 45, 345-371.

Tomlinson M, Walker R and Williams G (2009) Measuring poverty in Britain as a multi dimensional concept, 1991 to 2003. Journal of Social Policy 37, 597-620.

van der Maesen L and Walker A (eds) (2012) Social Quality: From Theory to Indicators. Palgrave, Basingstoke, UK.

Veenhoven R (1988) The utility of happiness. Social Indicators Research 20, 333-354.

Waddell EL and Jacobs-Lawson JM (2010) Predicting positive well-being in older men and women. International Journal of Aging and Human Development 70, 181-197.

Walker A (1981) Towards a political economy of old age. Ageing \& Society 1, 73-94.

Walker A (1984) Social Planning. Oxford: Blackwell.

Walker A (2009) Why is ageing so unequal? In Cann P and Dean M (eds), Unequal Ageing. Bristol, UK: Policy Press, pp. 141-158.

Walker A and Walker C (eds) (1997) Britain Divided: The Growth of Social Exclusion in the 1980s and 1990s. Child Poverty Action Group, London.

Wilkinson R and Pickett A (2009) The Spirit Level. Penguin, London.

Willets D (2013) Robbins Revisited: Bigger and Better Higher Education. Social Marketing Foundation, London.

Yee J and Chang D (2011) Social quality as a measure for social progress. Development and Society 40, $153-173$. 


\section{Appendix}

\section{Standardised covariates in the models and fit statistics for all four domains}

Table A1. Factor 1: Socio-economic security

\begin{tabular}{|c|c|c|c|}
\hline & Economic security & Housing/environment & Health \\
\hline Age 65-69 & NS & NS & NS \\
\hline Age $70-74$ & NS & NS & NS \\
\hline Age $75-79$ & NS & NS & $-0.281^{\star \star}$ \\
\hline Age $80+$ & $0.235^{\star}$ & NS & $-0.580^{\star \star}$ \\
\hline Female & NS & NS & $-0.199^{\star \star}$ \\
\hline Log income & $0.459^{\star \star}$ & NS & NS \\
\hline Single & NS & NS & NS \\
\hline \multicolumn{4}{|l|}{ Fit statistics: } \\
\hline $\mathrm{CFI}$ & 0.977 & & \\
\hline TLI & 0.973 & & \\
\hline RMSEA & 0.028 & & \\
\hline $\mathrm{N}$ & 2,130 & & \\
\hline
\end{tabular}

Notes: The reference groups are: age under 65, male and couple. CFI: Comparative Fit Index. TLI: Tucker-Lewis Index. RMSEA: Root Mean Square Error of Approximation.

Significance levels: Significant at: ${ }^{*} 5$ per cent level, ${ }^{* *} 1$ per cent level. NS: not significant.

Table A2. Factor 2: Social cohesion

\begin{tabular}{|c|c|c|c|c|}
\hline & Trust & Altruism & Social networks & Identity \\
\hline Age 65-69 & NS & NS & NS & NS \\
\hline Age $70-74$ & $0.583^{\star}$ & NS & NS & $0.289^{\star}$ \\
\hline Age $75-79$ & NS & $-0.445^{\star \star}$ & NS & $0.460^{\star \star}$ \\
\hline Age $80+$ & $0.712^{\star \star}$ & $-0.758^{\star \star}$ & NS & $0.491^{\star \star}$ \\
\hline Female & NS & $0.152^{\star}$ & NS & $0.169^{\star}$ \\
\hline Log income & $0.388^{\star \star}$ & $0.213^{\star \star}$ & NS & NS \\
\hline Single versus couple & NS & NS & NS & NS \\
\hline \multicolumn{5}{|l|}{ Fit statistics: } \\
\hline $\mathrm{CFI}$ & 0.919 & & & \\
\hline TLI & 0.883 & & & \\
\hline RMSEA & 0.042 & & & \\
\hline $\mathrm{N}$ & 1,901 & & & \\
\hline
\end{tabular}


Table A3. Factor 3: Social inclusion

\begin{tabular}{|c|c|c|c|}
\hline & Citizenship & Services & Social networks \\
\hline Age 65-69 & NS & NS & NS \\
\hline Age $70-74$ & $0.376^{\star \star}$ & NS & NS \\
\hline Age $75-79$ & $0.342^{\star \star}$ & NS & NS \\
\hline Age $80+$ & $0.513^{\star \star}$ & NS & NS \\
\hline Female & $-0.201^{\star \star}$ & NS & NS \\
\hline Log income & $0.143^{\star \star}$ & NS & $0.129^{\star}$ \\
\hline Single versus couple & $-0.185^{\star}$ & NS & $-0.362^{\star \star}$ \\
\hline \multicolumn{4}{|l|}{ Fit statistics: } \\
\hline $\mathrm{CFI}$ & 0.962 & & \\
\hline TLI & 0.948 & & \\
\hline RMSEA & 0.028 & & \\
\hline $\mathrm{N}$ & 1,712 & & \\
\hline
\end{tabular}

Notes: See Table A1.

Significance levels: See Table A1.

Table A4. Factor 4: Empowerment

\begin{tabular}{|c|c|c|c|}
\hline & Knowledge & Time & Culture/participation \\
\hline Age 65-69 & $-0.254^{\star \star}$ & NS & NS \\
\hline Age $70-74$ & $-0.378^{\star \star}$ & $0.220^{\star}$ & $-0.307^{\star \star}$ \\
\hline Age $75-79$ & $-0.722^{\star \star}$ & NS & $-0.581^{\star \star}$ \\
\hline Age $80+$ & $-1.014^{\star \star}$ & NS & $-0.885^{\star \star}$ \\
\hline Female & $-0.212^{\star \star}$ & NS & NS \\
\hline Log income & $0.492^{\star \star}$ & NS & $0.205^{\star \star}$ \\
\hline Single versus couple & $-0.575^{\star \star}$ & $-0.173^{\star \star}$ & NS \\
\hline \multicolumn{4}{|l|}{ Fit statistics: } \\
\hline $\mathrm{CFI}$ & 0.936 & & \\
\hline TLI & 0.909 & & \\
\hline RMSEA & 0.055 & & \\
\hline $\mathrm{N}$ & 2,203 & & \\
\hline
\end{tabular}

Notes: See Table A1.

Significance levels: See Table A1.

Cite this article: Foster L, Tomlinson M, Walker A (2019). Older people and Social Quality - what difference does income make? Ageing \& Society 39, 2351-2376. https://doi.org/10.1017/S0144686X1800048X 